\title{
CLINICAL PROFILE OF OPTIC NEUROPATHY
}

\author{
Ramesh Ramachandra1 ${ }^{1}$ Deepthi Kiran², Kirthitheja Bommakanti³, Nikhil Goli ${ }^{4}$
}

${ }_{1}^{1}$ Associate Professor, Department of Neurology, Osmania General Hospital, Hyderabad, Telangana, India.

${ }^{2}$ Senior Resident, Department of Neurology, Osmania General Hospital, Hyderabad, Telangana, India.

3 Senior Resident, Department of Neurology, Osmania General Hospital, Hyderabad, Telangana, India.

${ }^{4}$ Senior Resident, Department of Neurology, Osmania General Hospital, Hyderabad, Telangana, India.

ABSTRACT

\section{BACKGROUND}

Optic neuropathy is a frequent cause of vision loss encountered in clinical practice. It is important to diagnose and treat the condition in a timely manner to prevent visual disability. The diagnosis is made primarily on clinical grounds. A rapid onset is typical of demyelinating, inflammatory, ischaemic and traumatic causes. A gradual course points to compressive, toxic/ nutritional and hereditary causes.

The aim of this study was to evaluate the clinical profile of Optic Neuropathy.

\section{MATERIALS AND METHODS}

All patients presenting to Osmania General Hospital with visual loss and those referred from Sarojini Devi Eye Hospital with optic neuropathy were included in the study. All these patients had already undergone ophthalmic examination, detailed clinical history, complete neurological examination, imaging and special investigations as required.

\section{RESULTS}

The highest incidence of optic neuropathies was seen in the age group of 21 - 30 years with female preponderance, presentations were unilateral bilateral simultaneously and sequentially. Painful vision loss was seen in $42 \%$ of cases. RAPD was seen in 21 patients on the whole in our study. Disc oedema and blurring with or without haemorrhages were seen in 19 (38\%) patients. Most patients had an abnormal VEP in the form of either a delayed P100 or a reduced amplitude. The CSF proteins were increased in $22 \%$ of the patients and Oligoclonal bands were seen in 5 patients. Demyelination is the most common cause followed by ischaemia and other causes.

\section{CONCLUSION}

Optic neuritis was found to be the commonest cause of optic neuropathy in this study. A detailed clinical examination especially fundoscopy, imaging, CSF analysis are required to arrive at aetiology of optic neuropathy.

\section{KEY WORDS}

Optic Neuropathy, RAPD, Dyschromatopsia, Visually Evoked Potentials.

HOW TO CITE THIS ARTICLE: Ramachandra R, Kiran D, Bommakanti K, et al. Clinical profile of optic neuropathy. J. Evolution Med. Dent. Sci. 2018;7(24):2880-2884, DOI: 10.14260/jemds/2018/649

\section{BACKGROUND}

Optic neuropathy is a frequent cause of vision loss encountered in clinical practice. It is important to diagnose and treat the condition in a timely manner to prevent visual disability. The diagnosis is made primarily on clinical grounds. The history often points to the possible aetiology of optic neuropathy. A rapid onset is typical of demyelinating, inflammatory, ischaemic and traumatic causes. A gradual course points to compressive, toxic/ nutritional and hereditary causes. The classic clinical signs of optic neuropathy are diminished vision, visual field defects, dyschromatopsia and abnormal pupillary response. There are ancillary investigations that can support the diagnosis of optic neuropathy. Visual field testing by either manual kinetic or automated static perimetry is important in the diagnosis.

'Financial or Other Competing Interest': None.

Submission 17-03-2018, Peer Review 28-05-2018,

Acceptance 04-06-2018, Published 11-06-2018.

Corresponding Author:

Ramesh Ramachandra,

16-10-27/9 632 RT, Flat 101,

Municipal Colony, Old Malakpet,

Hyderabad, Telangana, India.

E-mail: ramrameshneuro@gmail.com

DOI: $10.14260 /$ jemds $/ 2018 / 649$
Neuroimaging of the brain and orbit is essential in many optic neuropathies including demyelinating and compressive. Other technologies that aid in the evaluation of optic neuropathies include multifocal visual evoked potentials and optical coherence tomography. ${ }^{1}$

\section{Objective}

To study the Clinical Profile of Optic Neuropathy.

\section{MATERIALS AND METHODS}

This is a case series. All the patients presenting to Osmania General Hospital with visual loss and those referred from Sarojini Devi Eye Hospital with optic neuropathy were included in the study. All these patients had already undergone ophthalmic examination at Sarojini Devi Eye Hospital. Detailed clinical history was taken from each of the patients regarding vision loss, photopsia and colour desaturation. Complete neurological examination was performed on all the patients. Visual acuity was checked in all patients using Snellen's chart. Colour vision and visual fields using the confrontation method were tested. Pupillary reactions, direct and consensual were done in all and the presence or absence of RAPD was noted in all patients. Fundus examination was performed using the direct ophthalmoscope. All the patients were subjected to pattern 
reversal visual evoked response. In patients with severe visual loss, flash VEP was done. Visual field testing was prescribed for all patients, but could not be performed in few patients with severe visual loss. Routine investigations like Complete Blood Picture, Complete Urine Examination, ESR, Renal Function Tests, Liver Function Tests, HIV and HBsAg were done in all patients. All the patients were subjected to imaging of brain and orbits. Imaging of spine was done in patients suspected of having neuromyelitis optica and those presenting with features of myelopathy. MRI brain and orbits was done to detect traumatic, compressive lesions and to look for optic atrophy in chronic cases. MRI brain was also performed to detect white matter lesions consistent with multiple sclerosis or neuromyelitis optica in cases with optic neuritis. In cases with active demyelinating lesions and tumours of the brain, orbits or spine gadolinium enhanced MRI was done. CSF analysis was done in all patients with optic neuritis and in cases suspected to have infective or infiltrative pathology. CSF was sent for routine biochemical, pathological, microbiological examination. In addition to this, ADA levels were sent for cases with suspected tuberculosis. Oligoclonal bands in the CSF were sent for patients with optic neuritis. This test could not be performed in all the cases due to financial constraints. Serum NMO antibodies (Aquaporin4) were sent for in all the cases with bilateral optic neuritis and those with myelopathy. In male cases with chronic bilateral visual loss with optic atrophy and normal imaging genetic analysis for LHON mutations was sent. LHON is classically associated with mitochondrial base pair mutations G11778A (guanine to adenine at position 11778), T14484C (tyrosine to cytosine) and G3460A. All these mutations were tested in this subgroup of patients. Clinical data and the data from investigations of all the patients was analysed and results tabulated.

\section{RESULTS}

\section{Age Group}

The highest incidence (34\%) of optic neuropathies were seen in the age group of $21-30$ years. Three patients (6\%) presented to us in the first decade, 6 patients $(12 \%)$ presented in the second decade. Highest number of cases, 17 cases presented to us in the third decade followed by 12 cases (24\%) with onset in the fourth decade. 6 patients $(12 \%)$ were seen in the fifth and 4 cases in the sixth decade (8\%). 2 patients (4\%) presented in the seventh decade.

\section{Sex Distribution}

Out of the 50 cases analysed in our study, 23 were males and 27 were females.

\section{Unilateral or Bilateral Presentation}

Optic neuropathies can have a unilateral, bilateral simultaneous or consecutive involvement. Unilateral presentation was seen in 27 patients and bilateral in 23 patients in this study. Of the cases presenting bilaterally, 7 patients had simultaneous bilateral presentation and 16 of our cases had sequential bilateral involvement. In the subset of optic neuritis cases, 18 cases had a unilateral presentation and 8 cases had bilateral presentation.

\section{Eye Pain}

Painful vision loss was seen in 21 cases (42\%) in our study, while 29 cases (58\%) had a painless clinical presentation. In the optic neuritis subset, 18 out of 26 cases (69.2\%) had eye pain at presentation in form of pain at rest or painful eye movements.

\section{Relative Afferent Pupillary Defect}

RAPD was seen in 21 patients on the whole in our study. Out of 27 cases of unilateral optic neuropathy, RAPD was seen in 19 patients. Relative afferent pupillary defect was seen in only two cases with bilateral optic neuropathy in our study.

\section{RAPD in Optic Neuritis}

Out of the 26 cases with an aetiology of demyelination, 19 patients had RAPD and the other 7 did not have RAPD.

\section{Fundus}

Fundus examination was performed in all patients using direct ophthalmoscope. Normal fundus picture was seen in 13 patients (26\%). Pale disc signifying optic atrophy was seen in18 (36\%) patients. Disc oedema and blurring with or without haemorrhages were seen in 19 (38\%) patients.

\section{Field Defects}

Altitudinal field defects were seen in 4 patients. All these patients had NAION. Central scotomas were seen in 13 patients in our study. Centrocaecal scotoma was seen in 5 patients. 10 cases of optic neuritis showed central and centrocaecal field defects.

\section{Visual Evoked Potentials}

In our study, most patients $(n=45 / 50)$ had an abnormal VEP in the form of either a delayed P100 or a reduced amplitude. In 5 cases, VEP could not be elicited.

\section{CSF Analysis}

The CSF proteins were increased in $22 \%$ of the patients and oligoclonal bands were seen in 5 patients. The CSF analysis was normal in 20 cases.

\section{Imaging}

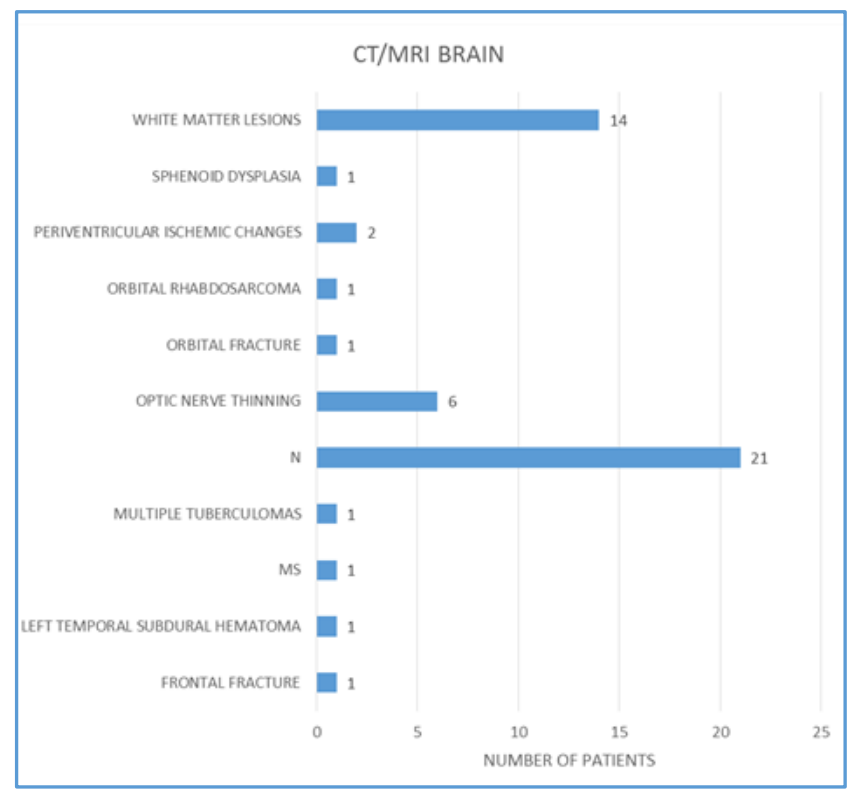




\section{Aetiology}

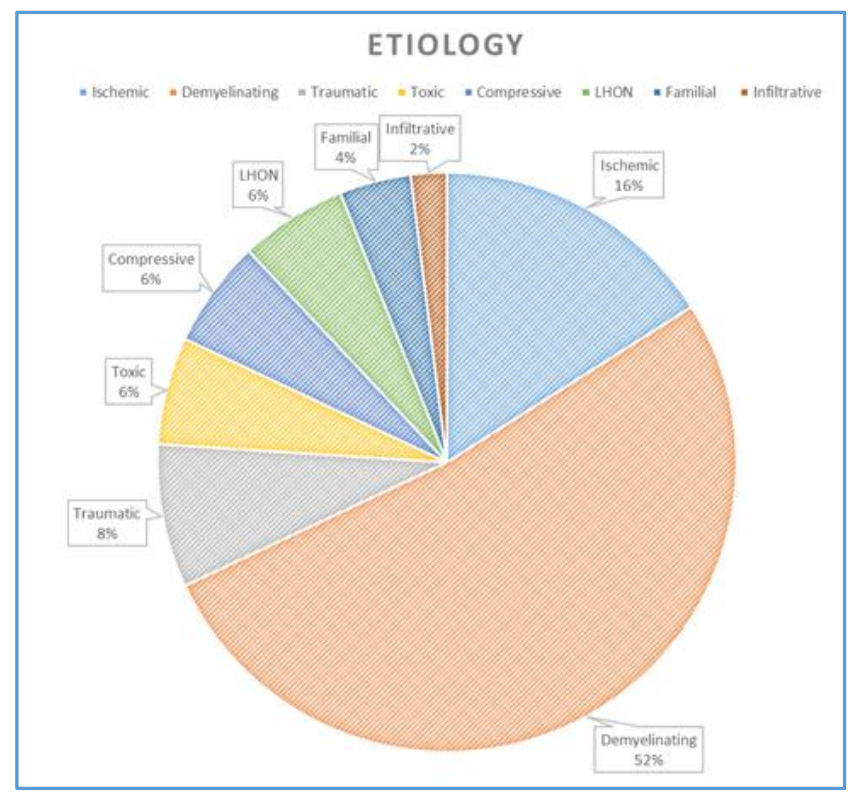

\section{DISCUSSION}

Age

The highest incidence (20\%) of optic neuropathies were seen in the age group of 21 - 30 years. Three patients (6\%) presented to us in the first decade and 6 patients (12\%) presented in the second decade. Highest number of cases, 17 cases presented to us in the third decade followed by 12 cases (24\%) with onset in the fourth decade.

Optic neuritis is more common in females with a peak age of onset between 30 and 40 years in a study done by Beck et al. ${ }^{2}$ In our study, the peak age group was even younger with the maximum number of patients belonging to the age group between 20 and 30 with an average age of 28.72 years. In addition the patients with NMO were younger than the others with an average of presentation being 22.28 years which was similar to the results seen in the study done by Cabre et al. $^{3}$ Optic neuritis in children is classically thought to differ from adult optic neuritis by frequent bilateral involvement and disc swelling and more severe initial vision loss. ${ }^{1}$ In the present study, only 3 patients were under or at the age of 18 years. All of them had an acute onset and severe visual loss at presentation. NAION is a disease of the elderly and patients are usually above the age of 50 years and most studies show that the frequency of NAION increases with age.4,5 Similarly, the average age of patients with NAION was 52.25 years and $62.5 \%$ had hypertension and 50\% were diabetics in the present study. Leber's hereditary mitochondrial optic neuropathy (LHON) classically presents with acute unilateral painless visual loss.

\section{Sex}

Female predisposition with optic neuritis is well established and the findings in the present study correlate with those findings. ${ }^{3}$ They constituted $61.5 \%$ of the cases in this study with males accounting for the rest $38.5 \%$, which is similar to the incidence seen in ONTT which had a female incidence of $77 \%$. The other aetiological conditions causing optic neuropathy usually do not have a gender predilection.
In LHON, males are more likely to be affected as seen in study by Seedorff T et al. ${ }^{6}$ The 3 patients with LHON in our study also were males, which was similar to the results.

\section{Onset}

Optic neuritis typically presents in an acute fashion with an abrupt loss of vision. Most patients describe diffuse blurred vision, although some state that blurring is predominantly central. Some patients with a predominantly peripheral involvement may deny loss of central acuity and may be found to have a vision of $20 / 20 .^{7}$ However, all the patients with optic neuritis in the present study had loss of central vision and moderate-to-severe diminished vision.

NAION typically presents as sudden, painless loss of vision in one or both the eyes. ${ }^{8}$ The same findings were also found in the present study with all the patients presenting with sudden painless loss of vision. Patients with hereditary optic neuropathies characteristically present with a gradual and progressive loss of vision. All patients with LHON $(n=3)$ in our study also had a gradual loss of vision. Compressive optic neuropathy is associated with a gradual loss of vision and proptosis. ${ }^{9}$

\section{Presentation}

Diminished vision was the chief complaint in 48 out of the 50 patients who presented to us. One patient presented with the complaint of photopsia and one patient had colour desaturation. In all, 29 patients had painless loss of vision and the remaining 21 had painful loss of vision. Demyelination was the predominant cause of painful loss of vision with 4 patients with traumatic optic neuropathy also having eye pain. Painless loss of vision was seen in all the patients who had NAION and compressive optic neuropathy, which was similar to findings in the study done by Sibony et al and Sarkies NJ.10,11

\section{Fundus}

Overall, the optic disc was normal in appearance in $26 \%$ cases with blurred disc being found in 38\% and optic disc atrophy was seen in 36\%. In 1973, Norris WF et al reported a triad of signs ${ }^{12}$ believed to be pathognomonic for LHON: circumpapillary telangiectatic microangiopathy, swelling of the nerve fibre layer around the disc (Pseudo-oedema) and absence of leakage from the disc or papillary region on fluorescein angiography (distinguishing the LHON nerve head from truly oedematous discs). In a review published by Behbehani, ${ }^{1}$ the fundus was normal in $75 \%$ patients with optic neuritis. The disc was normal in $46.1 \%$ in our study and disc blurring was seen in $38.4 \%$. The higher incidence of disc blurring in our study can be attributed to the fact that the patients presenting to us were at an advanced stage. Anterior injuries between the globe and where the central retinal vessels enter the optic nerve produce disturbances in the retinal circulation including venous obstruction and traumatic anterior ischaemic optic neuropathy. ${ }^{13}$ Haemorrhages in the optic nerve sheath posterior to the origin of the central retinal vessels may leave the circulation of the retina intact, but produce optic nerve head swelling. ${ }^{14}$

\section{RAPD}

In all, 21 patients had RAPD and it was absent in 29 patients. Optic neuritis is associated with RAPD in almost all the 
cases. $^{15}$ It was present in $83.3 \%$ cases with unilateral presentation. In cases where RAPD was not found in optic neuritis, the fellow eye was involved. RAPD was also seen in 2 cases with NAION and in 1 case with traumatic optic neuropathy.

\section{CSF Analysis}

In the present study, pleocytosis was seen in $25 \%$ of the cases and oligoclonal bands were seen in 6 out of the 9 cases (66.6\%) investigated. (Note: Oligoclonal band testing was not performed in the rest because of financial constraints) contrast to Frankstein et al ${ }^{16}$ Soderstrom reported that oligoclonal IgG bands were present in $69 \%$ of patients with optic neuritis. ${ }^{17}$ Toxic optic neuropathy was seen in 3 cases, out of which 2 cases were the result of treatment for tuberculosis. The CSF analysis in these cases showed a leukocytosis along with an increase in proteins, which is the expected finding in cases with TBM.

\section{Visual Evoked Potentials}

In a study done by Klistorner et al, they found ${ }^{18}$ a delay in the P100 of the visual evoked response. Similarly, in our study most patients $(n=46 / 50)$ had an abnormal VEP in the form of either a delayed P100 or reduced amplitude.

\section{Visual Fields}

Keltner and Johnson began characterising the types and severity of visual field defects in the ONTT. ${ }^{19}$ Almost all the patients with optic neuritis have abnormal visual fields and though the central scotoma is classically found in cases of optic neuritis almost any type of field defect can be seen. Central or centrocaecal scotoma was the predominant finding in optic neuritis (which was seen in $70 \%$ cases) in our study, which was similar to the findings observed in the study done by Gerling J et al. ${ }^{20}$ All the cases with LHON had central field defects, which is consistent with the study done by Vansenus $\mathrm{AH}$ et al. ${ }^{21}$ Altitudinal field defects were seen in $60 \%$ of the cases with NAION.

\section{Imaging}

Two or more lesions on brain MR imaging of patients with isolated optic neuritis were reported by Miller et al in $64 \%$ of 53 patients less than 50 years old who were scanned $1-40$ weeks after onset.22 In the ONTT, only $27 \%$ of patients had two or more signal abnormalities at least $3 \mathrm{~mm}$ in size. ${ }^{6}$ In the present study, $57.7 \%$ cases with optic neuritis had white matter lesions in the brain. Most of the subjects with NAION had a normal study on brain imaging, but 1 patient had periventricular ischaemic changes.

\section{Aetiology}

Demyelination was the most common cause in our study accounting for 26 patients. Of these cases, 7 patients were fulfilling criteria for neuromyelitis optica at the time of diagnosis and one patient fulfilled criteria for multiple sclerosis. Next common cause was ischaemic pathology accounting for 8 cases. All the 8 cases were of anterior ischaemic optic neuropathy. All of them belonged to the nonarteritis type (NAION). Traumatic was the next common cause seen in 4 patients with orbital and frontal fractures as the cause. Compressive aetiology was seen in 3 patients, 1 has orbital rhabdomyosarcoma, another had multiple tuberculomas compressing the optic nerve. One patient has sphenoid wing dysplasia as the cause; 3 cases of LHON were seen in our study. All of them were male patients and had positive mutations for LHON.

Two cases of AD optic atrophy were seen. Both were siblings aged 6 and 5 years who presented with chronic progressive visual loss. In this study one case had infiltrative aetiology, neurosarcoidosis which is a less common cause of optic neuropathy.

\section{CONCLUSION}

Optic neuritis was found to be the commonest cause of optic neuropathy in this study. A detailed clinical examination especially fundoscopy, imaging and CSF analysis are required to arrive at aetiology of optic neuropathy.

\section{REFERENCES}

[1] Behbehani R. Clinical approach to optic neuropathies. Clinical Ophthalmology (Auckland, NZ) 2007;1(3):233-46.

[2] Beck RW. The optic neuritis treatment trial: three-year follow-up results. Archives of Ophthalmology 1995;113(2):136-7.

[3] Cabre P, Heinzlef O, Merle $H$, et al. MS and neuromyelitis optica in Martinique (French West Indies). Neurology 2001;56(4):507-14.

[4] Tsai RK, Lee YH. Reversibility of Ethambutol optic neuropathy. Journal of Ocular Pharmacology and Therapeutics 1997;13(5):473-7.

[5] McCulley TJ, Lam BL, Feuer WJ. A comparison of risk factors for postoperative and spontaneous nonarteritic anterior ischemic optic neuropathy. Journal of Neuro-Ophthalmology 2005;25(1):22-4.

[6] Seedorff T. Leber's disease. Acta Ophthalmol 1968;46(1):4-25.

[7] Kupersmith MJ, Nelson JI, Seiple WH, et al. The 20/20 eye in multiple sclerosis. Neurology 1983;33(8):101520.

[8] Kerr NM, Chew SS, Danesh-Meyer HV. Non-arteritic anterior ischaemic optic neuropathy: a review and update. Journal of Clinical Neuroscience 2009;16(8):994-1000.

[9] Dutton JJ. Optic nerve gliomas and meningiomas. Neurol Clin 1991;9(1):163-77.

[10] Sibony PA, Kennerdell JS, Slamovits TL, et al. Intrapapillary refractile bodies in optic nerve sheath meningioma. Arch Ophthalmol 1985;103(3):383-5.

[11] Sarkies NJ. Optic nerve sheath meningioma: diagnostic features and therapeutic alternatives. Eye (Lond) 1987;1(Pt 5):597-602.

[12] Norris WF. Hereditary atrophy of the optic nerves. Trans Am Ophthalmol Soc 1884;3:622-78.

[13] Hupp SL, Buckley EG, Byrne SF, et al. Posttraumatic venous obstructive retinopathy associated with enlarged optic nerve sheath. Archives of Ophthalmology 1984;102(2):254-6.

[14] Crowe NW, Nickles TP, Troost BT, et al. Intrachiasmal hemorrhage: a cause of delayed post-traumatic blindness. Neurology 1989;39(6):863-5.

[15] Miller NR, Newman NJ, Hoyt WF, et al. Walsh and Hoyt's clinical neuro-ophthalmology. Baltimore: Williams \& Wilkins 1998. 
[16] Frederiksen JL, Larsson HB, Olesen J. Correlation of magnetic resonance imaging and CSF findings in patients with acute monosymptomatic optic neuritis. Acta Neurologica Scandinavica 1992;86(3):317-22.

[17] Söderström M, Lindqvist $M$, Hillert J, et al. Optic neuritis: findings on MRI, CSF examination and HLA class II typing in 60 patients and results of a shortterm follow-up. Journal of Neurology 1994;241(6):391-7.

[18] Fraser C, Klistorner A, Graham SL, et al. Multifocal visual evoked potential analysis of inflammatory or demyelinating optic neuritis. Ophthalmology 2006;113(2):315.e1-323.e2.
[19] Keltner JL, Johnson CA, Spurr JO, et al. Baseline visual field profile of optic neuritis. The experience of the optic neuritis treatment trial. Optic Neuritis Study Group. Arch Ophthalmol 1993;111(2):231-4.

[20] Gerling J, Meyer JH, Kommerell G. Visual field defects in optic neuritis and anterior ischemic optic neuropathy: distinctive features. Graefes Archive for Clinical and Experimental Ophthalmology 1998;236(3):188-92.

[21] Vansenus AH. Leber's disease in the Netherlands. Documenta Ophthalmologica 1963;17(1):1-162.

[22] Miller DH, Ormerod IE, McDonald WI, et al. The early risk of multiple sclerosis after optic neuritis. Journal of Neurology, Neurosurgery \& Psychiatry 1988;51(12):1569-71. 